\title{
Production of microcellular foam based on PP/EPDM: The effects of processing parameters and nanoclay using response surface methodology
}

\author{
Mohsen Keramati, Ismaeil Ghasemi, ${ }^{*}$ Mohammad Karrabi, Hamed Azizi \\ *Iran Polymer and Petrochemical Institute, P.O.Box:14965/115, Tehran, I.R. Iran; \\ e-mail: I.Ghasemi@ippi.ac.ir.
}

(Received: 18 May, 2011; published: 10 July 2012)

\begin{abstract}
Microcellular foam is a new class of material with superior properties due to smaller cell size and higher cell density compared to ordinary foams. In this work, microcellular foam of PP/EPDM/Organoclay with supercritical nitrogen as physical blowing agent was prepared via batch process. Experimental design was carried out according to Box-Behnken method and the effects of saturation pressure and foaming times as well as organoclay content on nucleation and final foam morphology were studied using response surface methodology (RSM). Three levels of saturation pressure, nanoclay content, and foaming time were chosen. The mathematical model and response surface graphs have been used to illustrate the relationship between considered parameters and foam properties. The results revealed that cell density and average cell diameter were affected by nanoclay content and pressure. Cell density was in the range of $10^{9}-10^{10} \mathrm{cell} / \mathrm{cm}^{3}$. Larger average cell sizes were observed as a result of increasing foaming time. Classic nucleation theory was used to study the nucleation mechanism. Nanoparticles acted as nucleating agents and changed nucleation mechanism from homogenous to heterogeneous by decreasing nucleating free energy. In order to find out nucleating energy reduction, gas-polymer-nanoparticle contact angle $(\Theta)$, was calculated by measuring surface and interfacial free energies of neat polymers and nanoparticle. In addition, nucleation efficiency of organoclay was estimated and the results showed that despite low nucleating efficiency, nucleation is dominated by presence of nanoclay.

Keywords: Microcellular foam, Classic nucleation, PP/EPDM Nanocomposite, Response Surface Methodology
\end{abstract}

\section{Introduction}

The idea of microcellular foam, a light weight material with voids less than polymer structural defects which exhibits excellent mechanical properties, was first introduced by Martini et al. In early 1980s [1]. Microcellular foams are new class of materials with cell sizes in the range of $10 \mu \mathrm{m}$ and cell density about $10^{9}-10^{15} \mathrm{cells} / \mathrm{cm}^{3}$.

To produce microcellular foams several methods have been designed. The main approach is to saturate polymer with an inert gas at high pressure and then imposing a thermodynamic instability to the system by weather pressure drop or temperature rise and finally controlling the cells which are nucleated in the former state [1-6].

It is well known that the higher cell density and the smaller cell diameters are desirable. Thus, numerous studies are carried out to investigate the effects of processing parameters on cell density, cell size, and final foam morphology of 
different polymers [7-11]. Also, a large body of papers is published on application of nucleating agents to create finer foam structure [12-16]. More recently, nanocomposite microcellular foams have gained great attention because high aspect ratio of nanoparticles leads to low nucleating energy barrier and surprising cell nucleation [17-21]. Wentao Zhai and coworkers used nanosilica in polycarbonate foam and their results revealed that uniform cell size distribution as well as a reduction in the average cell size was attained [22].

The shape of nano particles is another important factor that influences the foam morphology [23, 24]. Jiong Shen et al. showed that carbon nanofibers (CNF) had better nucleating efficiency compared to nanoclays and single-walled carbon nanotubes (SWCNT) in polystyrene [23].

Nanocomposite foams also exhibit significant enhancement of the mechanical properties. Even in some studies higher tensile and compressive moduli in comparison to unfoamed samples have been reported [17]. Dispersion of nanoparticles has a great effect on cell density $[18,23]$. Some studies reveal that higher degree of exfoliation is a key factor for increasing cell density [25].

Isotactic polypropylene (PP) is a semi-crystalline polymer with wide range of applications due to its excellent cost/properties ratio. Blending PP with ethylene propylene diene monomer (EPDM), makes PP more desirable for industrial applications because of impact behavior and toughness improvement [26, 27]. Recently, some attempts have been done to produce microcellular foam of this blend and thus achieve better cost/properties ratio [28].

In this study, microcellular foam based on PP/EPDM/Organoclay nanocomposite was produced via batch foaming process in a home-made autoclave. Effects of foaming pressure, foaming time and nanoclay concentration on the foam structure were studied. The foam morphology was evaluated by cell sizes, cell densities, and foam densities. To analyse the results, the response surface methodology (RSM) was employed. The mathematical model and response surface graphs were used to illustrate the relationship between considered parameters and foam morphology.

\section{Results and discussion}

In order to study the morphology of unfoamed samples, scanning electron microscopy was performed on the cryogenically fractured surfaces. SEM micrographs are presented in Figure 1. It is evident from the images that the predominant morphology of the blend is droplet-matrix in which the EPDM particles are dispersed into the PP matrix. In the neat sample without nanoparticles (sample $B_{1}$ ), the dispersed phase has irregular shape somehow between spherical and elongated droplets, but in the nanocomposite samples $\left(B_{2}, B_{3}, B_{4}\right)$ the EPDM domains tend to keep spherical shape. Image analysis of the micrographs revealed that the average diameter of the EPDM phase in the neat PP/EPDM blends is around $2 \mu \mathrm{m}$, while in nanocomposite samples it becomes a little finer. The finest dispersed size was observed for $B_{2}$ sample in which the average diameter of the droplets was around $1.3 \mu \mathrm{m}$.

It is important to evaluate the dispersion status of nanoparticles in the blend because the final foam morphology is highly dependent on the nanocomposite structure. Figure 2 shows the X-ray patterns of Cloisite 15A and the nanocomposite samples. The characteristic peak $\left(\mathrm{d}_{001}\right)$ for Cloisite $15 \mathrm{~A}$ appears at $2 \theta=2.8^{\circ}$ which corresponds to d-spacing of $31.5(\AA)$ between the original silicate layers. In $B_{2}$ and $B_{3}$ 
nanocomposite samples this peak has shifted to lower angles which are equal to 38.4 and $39.7 \AA \mathrm{d}$-spacing, respectively. This behavior could be attributed to intercalation of nanosilica layers in these blends. In addition, peak intensities are reduced from original peak of organoclay. Because of higher compatibilizer content, no definite peak is detected in $\mathrm{B}_{4}$ sample which can be a sign of exfoliation. Due to differences between polarities of polymers and nanofiller, use of compatibilizer to improve interaction is inevitable. Higher amount of compatibilizer leads to better filler dispersion because MA-g-PP penetrates between silicate layers and facilitates the exfoliation.

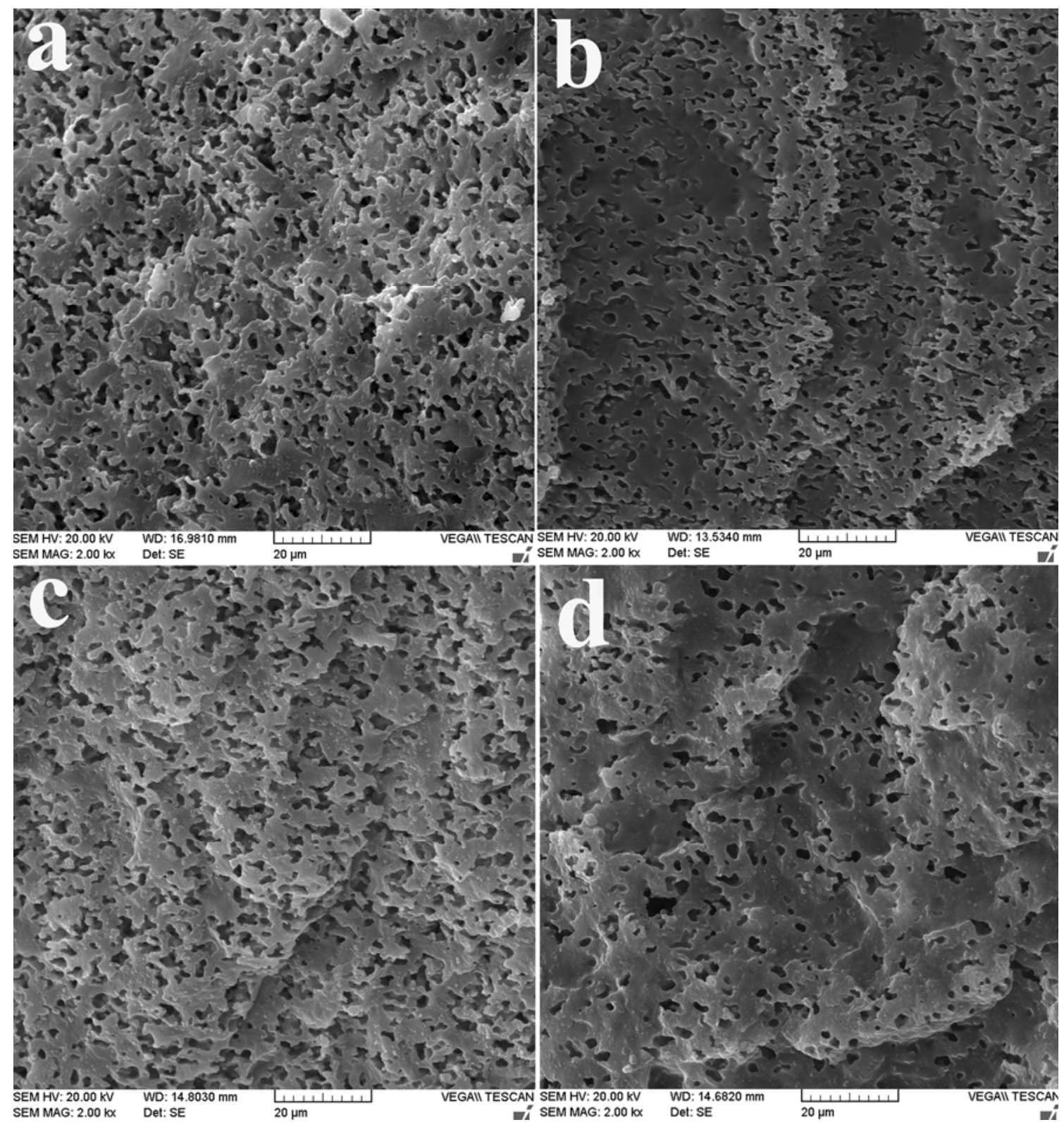

Fig. 1. SEM micrographs of unfoamed samples: (a) $B_{1}$, (b) $B_{2}$, (c) $B_{3}$, (d) $B_{4}$.

In order to get a better insight of nanoparticles dispersion, TEM test was done. Figure 3 represents TEM micrograph of sample $B_{4}$.TEM micrographs can provide only limited information about the elastomer phase due to the relatively small observable area at the magnifications needed to see the clay particles. 


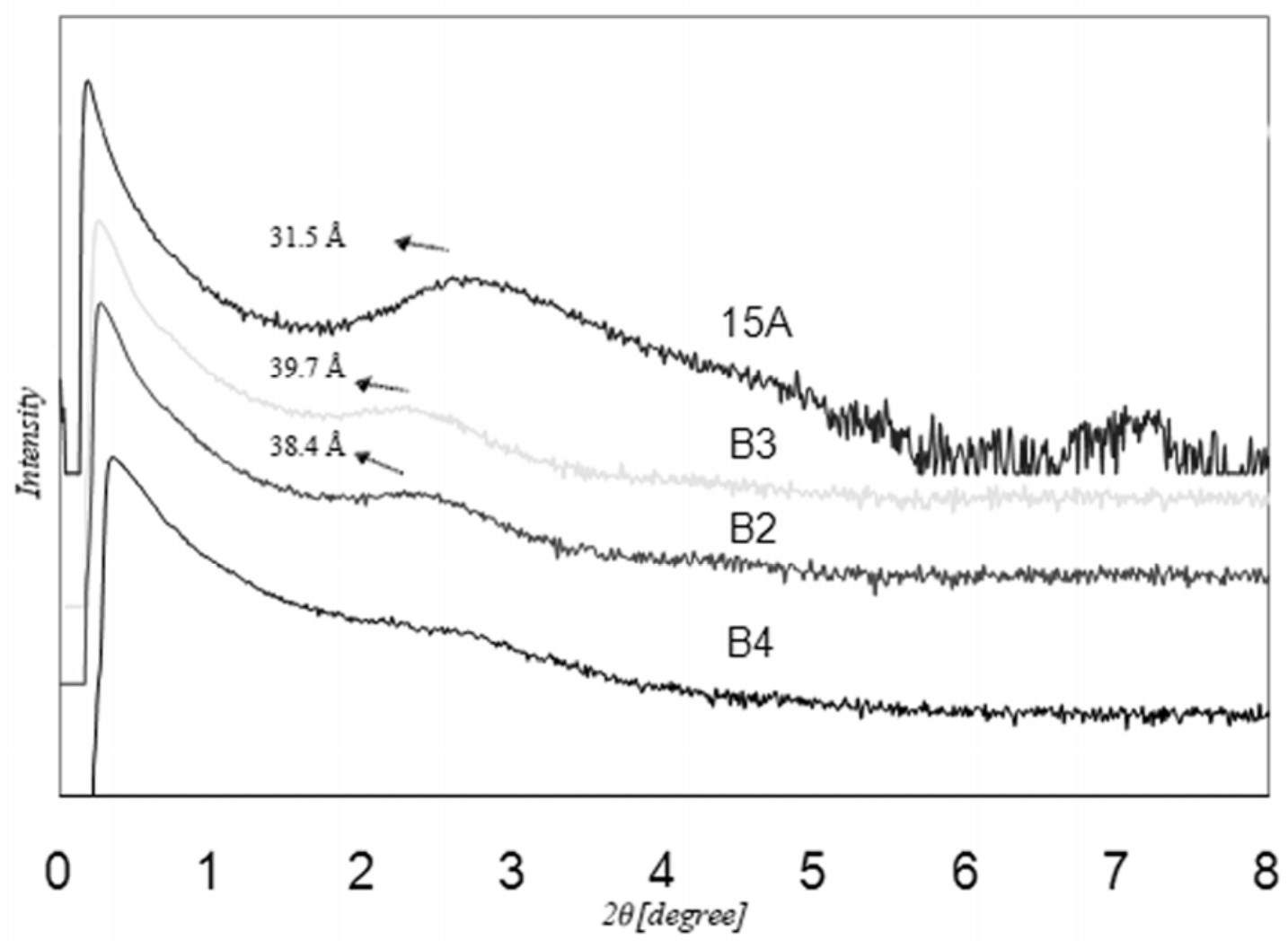

Fig. 2. XRD patterns of Cloisite $15 \mathrm{~A}$ and nanocomposite samples.

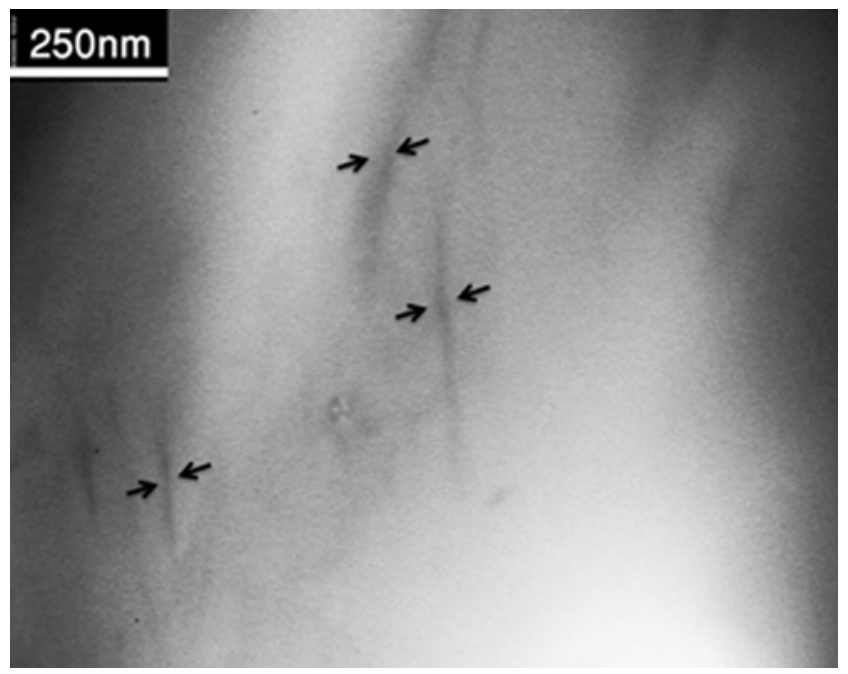

Fig. 3. TEM image of sample $B_{4}$.

The darker areas of the TEM image represent those areas of the sample that fewer electrons were transmitted through (they are thicker or denser). Thus, the black lines in the micrograph which are highlighted by arrows are supposed to be nanoclays. As observed in the image, nanosilicate layers are separated and the exfoliated state is attained. This result is in agreement with the X-ray pattern for sample $B_{4}$.

Since the main effect of the nanoparticles is in the nucleation step of foaming process, it is useful to consider the classic theory of nucleation. This theory, 
developed by Colton and Suh, describes bubble nucleation and growth in foams [16]. Based on this theory the homogeneous nucleation rate is given by:

$$
N_{\text {hom }}=f_{0} C_{0} \exp \left(\frac{-\Delta G_{\text {hom }}}{K T}\right)
$$

where $f_{0}$ is the frequency factor of the gas joining nucleus, $C_{0}$ is the concentration of the gas in the saturated sample, $\mathrm{K}$ is the Boltzmann constant, $\mathrm{T}$ is the absolute temperature and $\Delta \mathrm{G}_{\mathrm{hom}}$ is the homogeneous nucleation free energy that is defined by the following equation:

$$
\Delta G_{\mathrm{hom}}=\frac{16 \pi \gamma^{3}}{\Delta p^{2}}
$$

$\Delta p$ in Equation (2) is the pressure difference between that inside the critical nuclei and that the surrounding polymer. $\Delta p$ maybe taken to be equal to the saturation pressure in the vessel assuming the dissolved gas is an ideal gas and ${ }^{\gamma}$ is the surface energy of bubble- polymer interphase. Adding small amount of nanoclay changes nucleation mechanism to the heterogeneous one. the heterogeneous nucleation is energetically favoured and the nucleation rate is higher than that of the homogeneous. Equation (3) shows the heterogeneous nucleation rate.

$$
N_{\text {het }}=f_{1} C_{1} \exp \left(\frac{-\Delta G_{\text {het }}}{K T}\right)
$$

where $C_{1}$ is the nucleation sites, $f_{1}$ is the same as $f_{0}$ in Equation (3) and $\Delta G_{\text {het }}$ expressed as:

$$
\Delta G_{h e t}=\frac{16 \pi \gamma^{3}}{\Delta p^{2}} \frac{f(m, w)}{2}
$$

$f(m, w)$, [see Equation (5) ], is a function of nucleant-gas-polymer contact angle $(\theta)$ and the surface curvature of nucleating agent $(w)$. It is a reduction factor which decreases the nucleation free energy [30].

$$
f(m, w)=1+\left(\frac{1-m w}{g}\right)^{3}+w^{3}\left[2-3\left(\frac{w-m}{g}\right)+\left(\frac{w-m}{g}\right)^{3}\right]+3 m w^{2}\left(\frac{w-m}{g}-1\right)
$$

$m=\cos \theta$

$w=\frac{R}{r}$

$r=\frac{2 \gamma}{\Delta p}$

$g=\left(1+w^{2}-2 m w\right)^{1 / 2}$

Here, $\mathrm{R}$ is the nucleant radius. 
The typical reduction factor function versus the surface curvature for various $\theta$ is demonstrated in Figure 4(a) for a non-planner nucleating agent. As seen in the Figure 4(a) there are flat plate limits for high $w$ values. Infinite $w$ expresses the case of non-curvature particle surface, similar to the nanoclays which are used in this study. For the plate-like nucleant, the reduction factor becomes independent of $w$ and the Equation (5) changes to [31]:

$f(\theta)=\frac{1}{4}\left(2-3 \cos \theta+\cos \theta^{3}\right)$
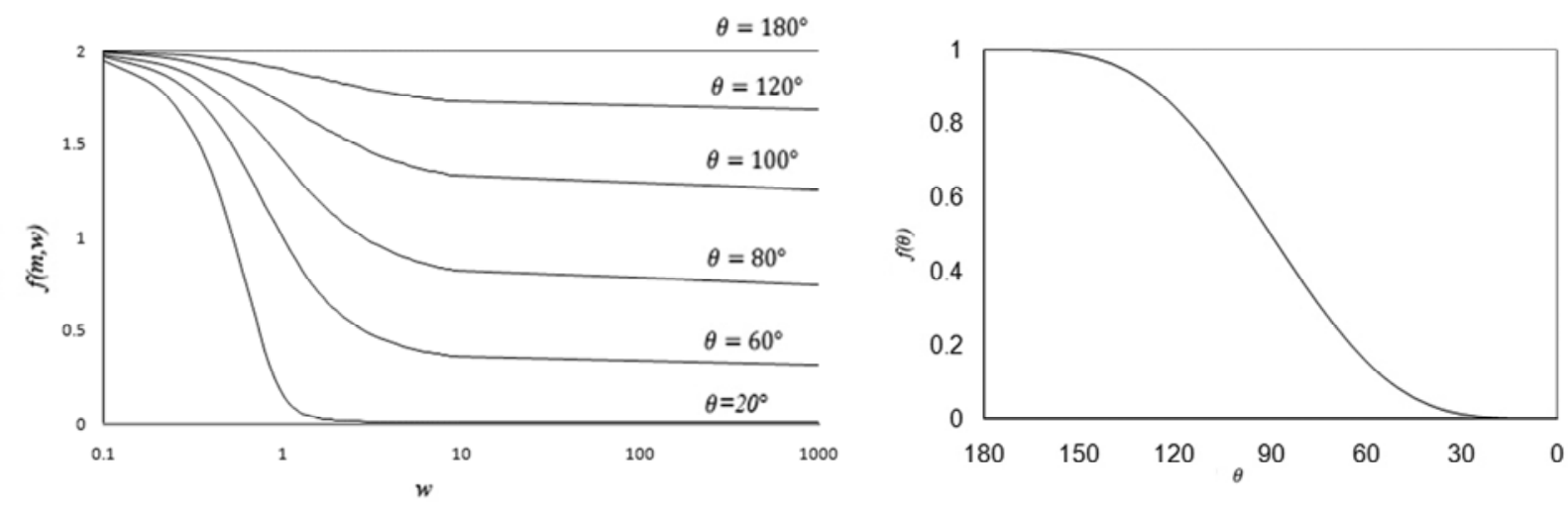

Fig. 4. (a) Reduction factor function versus surface curvature for various $\theta$, (b) reduction factor function versus $\theta$ for planner surface.

Figure 4(b) is obtained from Equation (6) which shows the independency of the reduction factor to the nucleant surface curvature. It also shows the reduction factor of nucleating energy barrier as a function of $\theta$. In other words, good interaction between polymer and the nanoparticles results in lower contact angle and lower nucleating energy barrier. Determination of contact angle in the polymer-gas-particle system is very difficult due to lack of literature data and complex interaction of parameters. In most cases a typical $\theta=20^{\circ}$ is considered to evaluate the nucleating free energy reduction of additives $[15,19,22]$. In current study, it has been tried to calculate an approximate value for $\theta$ using surface tension measurements. Figure 5 presents a schematic of bubble growth on a planner surface. Consider the nucleation of a gas bubble at the interface of a polymer and a solid particle, $\theta$ is the wetting angle of the interface. Equations (7) and (8) could be driven by balancing the surface tensions.

$\gamma_{13}=\gamma_{23}+\gamma_{12} \cos \theta$

$\theta=\cos ^{-1}\left(\frac{\gamma_{13}-\gamma_{23}}{\gamma_{12}}\right)$

Subscripts 1, 2, 3 are respectively represent the polymer matrix, the gas bubble, and the nanoclay planner surface.

The surface free energies of solids consist of polar and nonpolar components. The polar component originates from hydrogen bonding and permanent and induced dipoles intermolecular forces, while the nonpolar component is resulted from instantaneous moments [32]. Direct contact angle measurements were done via the 


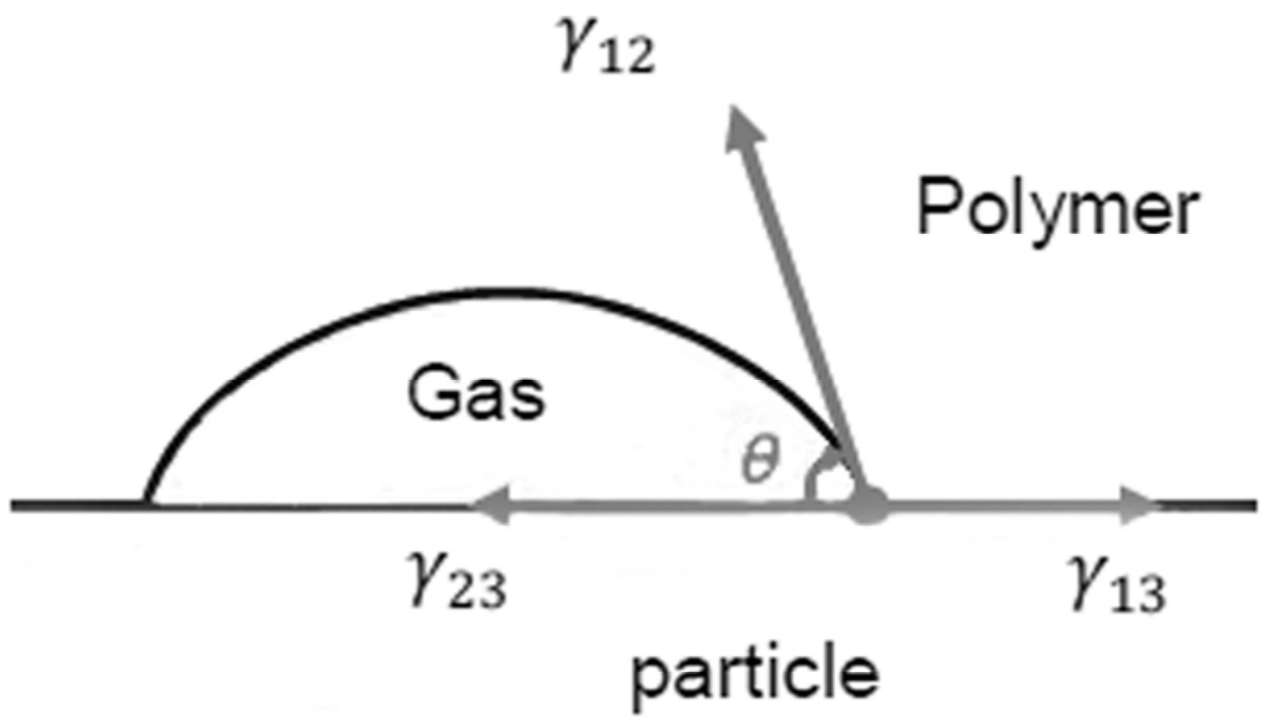

Fig. 5. Schematics of gas-polymer-particle interface.

Wu method to calculate the surface free energy of pure polymers and nanoclays. the surface free energy of pure $\mathrm{N}_{2}$ is approximately zero, while the interfacial tensions $\left(\gamma_{12}, \gamma_{13}, \gamma_{23}\right)$ were calculated according to the harmonic mean equation [33]:

$\gamma_{12}=\gamma_{1}+\gamma_{2}-4\left[\frac{\gamma^{d}{ }_{1} \gamma_{2}^{d}}{\gamma_{1}^{d}+\gamma_{2}^{d}}+\frac{\gamma_{2}^{p}{ }_{1} \gamma^{p}{ }_{2}}{\gamma^{p}+\gamma^{p}{ }_{2}}\right]$

where $\gamma_{1}$ and $\gamma_{2}$ denote the surface energies of components 1 and 2 respectively, and the $p, d$ indices stand for the polar and disperse components of the surface energy, respectively. the surface energies were measured at room temperature (25 $\left.{ }^{\circ} \mathrm{C}\right)$ and the temperature dependency $(-d \gamma / d T)$ was assumed to be 0.1 for nanoclay and 0.05 for polymers to obtain the values for the processing temperature [34]. Tables 1 and 2 show the obtained data for these parameters.

Tab. 1. Measured surface energies.

\begin{tabular}{lllll}
\hline Materials & $\begin{array}{l}\text { Surface energy } \\
\text { at } 25^{\circ} \mathrm{C}(\mathrm{mN} / \mathrm{m})\end{array}$ & $\begin{array}{l}\text { Surface } \\
\text { energy at } \\
152^{\circ} \mathrm{C}(\mathrm{mN} / \mathrm{m})\end{array}$ & $\begin{array}{l}\text { Dispersive } \\
\text { component at } 152^{\circ} \mathrm{C} \\
(\mathrm{mN} / \mathrm{m})\end{array}$ & $\begin{array}{l}\text { Polar } \\
\text { component at } \\
152^{\circ} \mathrm{C}(\mathrm{mN} / \mathrm{m})\end{array}$ \\
\hline $15 \mathrm{~A}$ & 34.24 & 21.54 & 17.92 & 3.62 \\
PP & 33.1 & 26.75 & 26.75 & 0 \\
EPDM & 29.58 & 23.23 & 23.23 & 0 \\
\hline
\end{tabular}

It should be noted that in order to avoid complication and because of good interaction between PP and Maleic anhydride grafted polypropylene ;MA-g-PP; it was assumed 
that they form a single phase and the data reported for PP considered the compatibilizer effect in fact.

Tab. 2. The interfacial energies calculated by harmonic mean equation.

\begin{tabular}{lll}
\hline System & Temperature $\left({ }^{\circ} \mathrm{C}\right)$ & $\begin{array}{l}\text { Interfacial energy calculated by } \\
\text { harmonic mean equation }(\mathrm{mN} / \mathrm{m})\end{array}$ \\
\hline $\mathrm{PP} / \mathrm{N}_{2}$ & 152 & 26.75 \\
$\mathrm{PP} / 15 \mathrm{~A}$ & 152 & 5.36 \\
& 152 & 23.23 \\
$\mathrm{EPDM} / \mathrm{N}_{2}$ & 152 & 4.30 \\
$\mathrm{EPDM} / 15 \mathrm{~A}$ & 152 & 21.54 \\
$15 \mathrm{~N} / \mathrm{N}_{2}$ & & \\
\hline
\end{tabular}

As mentioned earlier PP/EPDM is an immiscible blend and two distinct phases are detectable in SEM micrographs. Nucleation may be occurred in the individual phase (PP or EPDM) and interphase. Although it is possible for bubbles to nucleate at the interface of PP/EPDM, bubbles must grow up in PP or EPDM phase depending on their viscosity. Thus, two different values for $\theta$ are calculated, one for the PP-gasnanoparticle and the other stands for EPDM-gas-nanoparticle which are $127^{\circ}$ and $138^{\circ}$, respectively. The obtained polymer-gas-nanoparticle contact angles $(\theta)$ are higher than expectations which means no considerable reduction in free energy barrier has occurred. Jiong Shen et al. also used a plate-like surface-modified nanoclay (MHABS) to foam polystyrene and calculated the lower limit for $\theta$ to be $105.5^{\circ}$ in PP/CO2/MHABS system [23].

In order to get a better understanding of nanoparticles effect on the nucleation step and subsequently foam properties, mathematical models and surface responses are presented.

Final microcellular foam morphology is greatly dependent on processing parameters. In addition, presence of nanoparticles as the nucleating agent plays a important role in foam morphology. In this work, the cell density and the average cell diameter were selected as responses of the model because they are the main characteristics of the microcellular foam. Table 3 indicates the mathematical models and some statistical data for cell density and cell diameter. These equations are obtained from RSM methodology. $\mathrm{R}^{2}$ values are close to 1 which means that experimental data match the models and equations are valid for these responses. Values achieved for $\mathrm{R}^{2}$ in this study is an indication of a very good fitting of the experimental data by the response surface method in the models.

Tab. 3. Mathematical models for the cell density and the average cell diameter.

\begin{tabular}{lcc}
\hline Response & $\mathrm{R}^{2}$ & \multicolumn{1}{c}{ Equation of The Model } \\
\hline Cell Density & 0.926 & $54811510619-1211034653(\mathrm{P})-1017834252(\mathrm{~T})+$ \\
& & $5751337428(\mathrm{~N})+7276021\left(\mathrm{P}^{*} \mathrm{P}\right)-37789456\left(\mathrm{~T}^{*} \mathrm{~T}\right)+$ \\
& & $14600976\left(\mathrm{P}^{*} \mathrm{~T}\right)-44327793\left(\mathrm{P}^{*} \mathrm{~N}\right)$ \\
\hline Average & 0.962 & $5.51094-0.0343140(\mathrm{P})-0.0125884(\mathrm{~T})-1.31351(\mathrm{~N})+$ \\
Cell & & $0.00285478\left(\mathrm{~T}^{*} \mathrm{~T}\right)+0.0494525\left(\mathrm{~N}^{*} \mathrm{~N}\right)+0.00966391\left(\mathrm{P}^{*} \mathrm{~N}\right)$ \\
Diameter & & \\
\hline Pressure: $P$, Foaming Time: $T$, Nanoclay Content: $N$
\end{tabular}



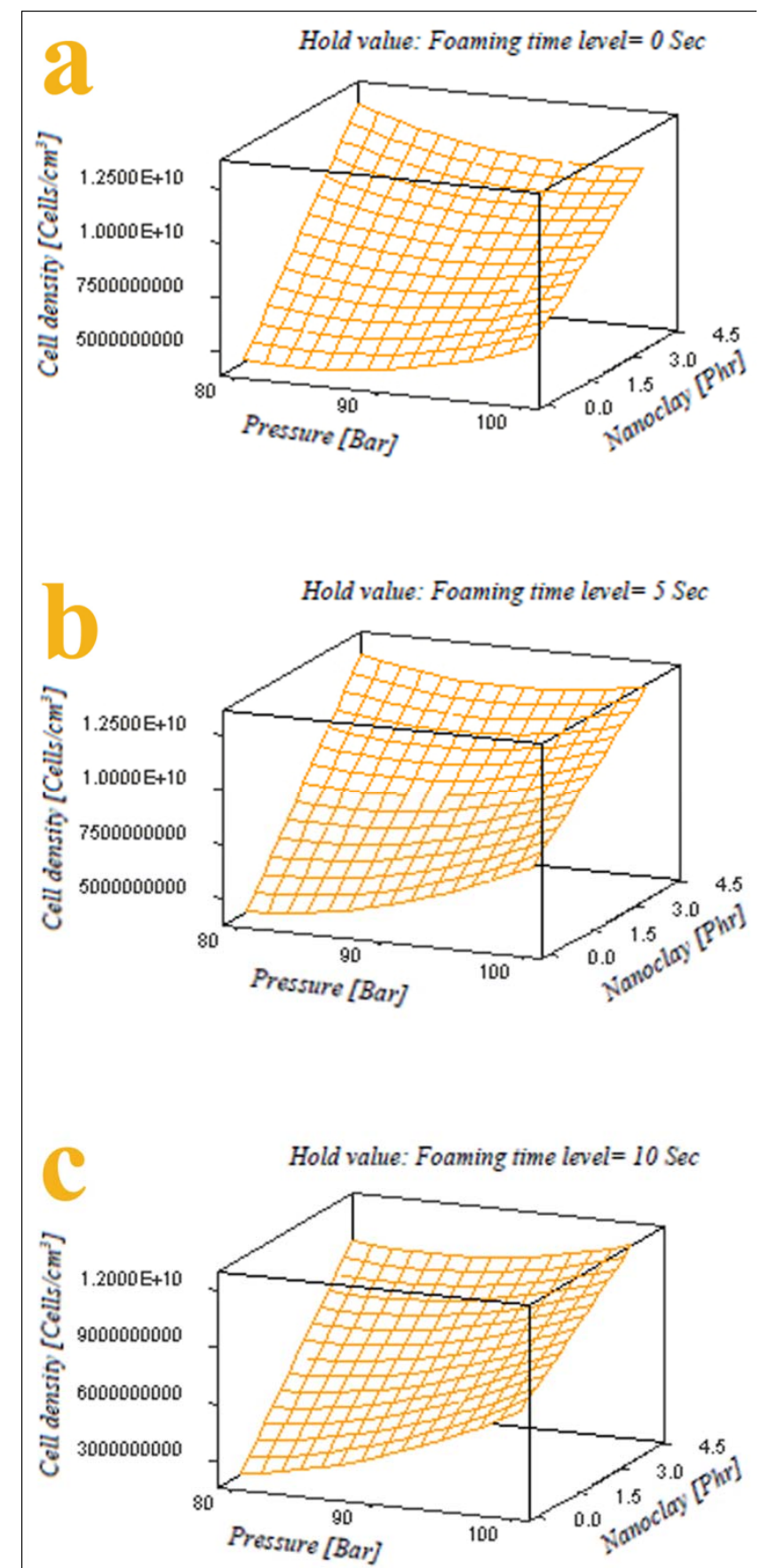

Fig. 6. Cell density versus saturation pressure and nanoclay content in three different foaming times.

Figure $6(\mathrm{a}, \mathrm{b}, \mathrm{c})$ demonstrates the cell density versus saturation pressure and nanoclay content in three different foaming time levels. As it is seen, higher cell density is obtained by increasing the saturation pressure and nanoclay concentration but the influence of nanoclay is more considerable. The higher saturation pressure may cause more nitrogen to be dissolved in polymer and therefore more bubbles can be nucleated. According to Equation (4), increasing the saturation pressure causes nucleation energy reduction and leads to higher nucleation rate and more cells are formed (higher cell density). On the other hand, because of constant depressurization time increasing the saturation pressure also leads to higher depressurization rate and increases bubble nucleation [35]. Despite high $\theta$ values, 
nanoclay showed drastic effect on cell density and the maximum cell density was in range of $10^{10}$ cells $/ \mathrm{cm}^{3}$. As it is observed in the Figure 6 the trend of increasing cell density by nanoclay loading is approximately constant which means more clay could have been added in order to obtain better results.
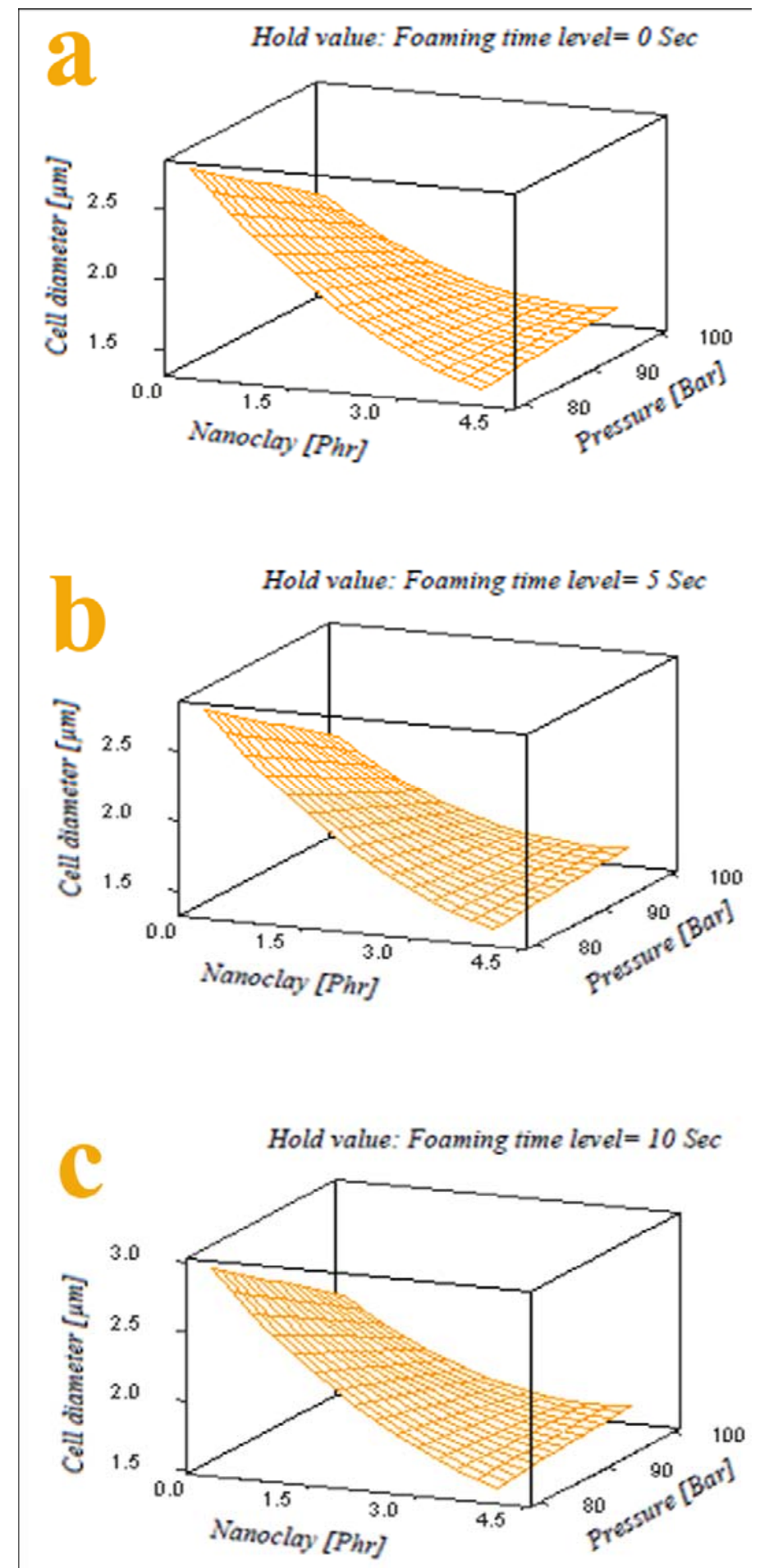

Fig. 7. The average cell diameter as a function of foaming pressure and nanoclay content in three different foaming times.

The results also revealed that the heterogeneous nucleation which is a result of nanoclay presence has greater effects on cell nucleation than the processing 
parameters. Another point is that the Box-Behnken design was carried out on samples $B_{1}, B_{2}$ and $B 3$ and these results were achieved with intercalation state. It is expected that exfoliation morphology leads to better nucleation and higher cell density.

The cell diameter is another important characteristic of microcellular foam that strongly affects foam properties. In contrast to cell density, lower values for cell size are desirable. Figure $7(a, b, c)$ presents the cell diameter as a function of foaming pressure and nanoclay content in three different foaming times. It is clear that a remarkable decrease in the average cell diameter has occurred by increasing nanoclay loading. The higher saturation pressure also has led to smaller cell size. By adding small amounts of nanoclay, due to the heterogeneous nucleation a large number of cells were nucleated. Therefore, most of the gas that is up taken to the polymer tends to participate in the nucleation process. As a result, the nitrogen supply in the saturated samples was depleted and less gas molecules were available for cell growth. As it is evident in the graphs, the average cell size variation trends are similar for three foaming time levels but the higher cell sizes are observed in longer foaming times.

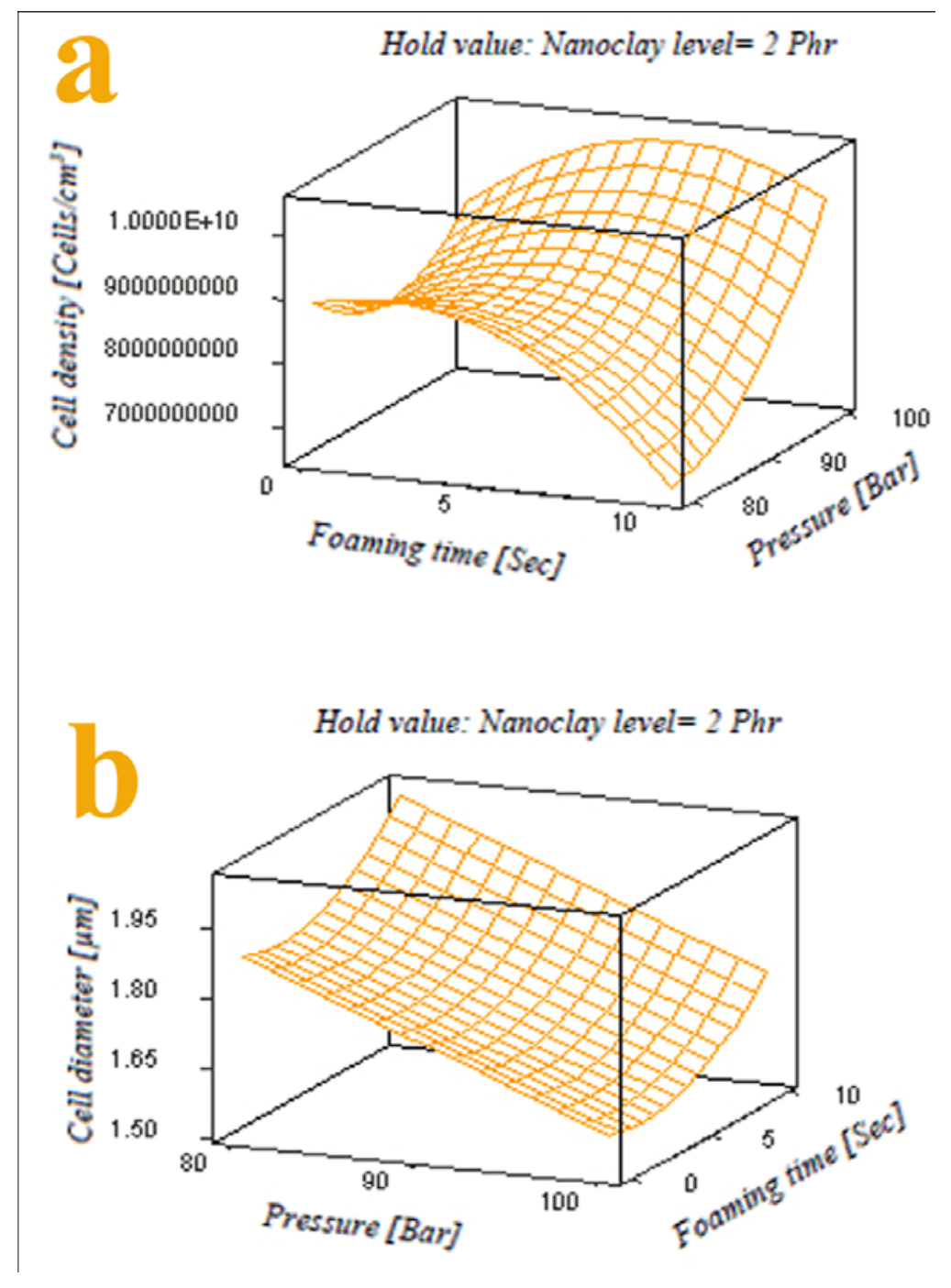

Fig. 8. (a) The cell density against foaming time and pressure and (b). The average cell diameter against foaming time and pressure. 
To highlight the influence of foaming time, the variation of the average cell diameter and the cell density against foaming time and pressure at a constant $2 \mathrm{Phr}$ nanoclay content is illustrated in Figure $8(a, b)$. In our experiments because of high saturation and foaming temperature, the foaming times were set to be short (maximum 10 seconds) to achieve finer cell structure. The obtained average cell diameters are around $2 \mu \mathrm{m}$ which is desirable.

In fact, the higher foaming time means more energy and time had been designated to the bubbles to grow larger. Cell growth continues until the foam becomes stable during cooling step. Zero foaming time in this experiment implies immediate cooling so that the bubbles are fixed at the first stage of growth. Immediate cooling may cause some bubbles to collapse before growing, so the cell density decreases and the rescued bubbles get more space to grow. Therefore, in Figure 8 (b) the average cell diameters show a minimum in about 5 seconds of foaming time and also a maximum in the cell density graph (Figure 8 (a)) can be seen. The finest foam structure is achieved in 5 seconds foaming time and $4 \mathrm{Phr}$ nanoclay loading, in which the average cell diameter reaches $1.5 \mu \mathrm{m}$. In the higher foaming times, cell coalescences may also occur among the growing neighbor cells. Some evidence of coalescences can be observed in the SEM micrographs (see Figure 9). Similar to cell density, the average cell diameters are influenced by foaming time and saturation pressure but apparently effect of nanoclay is dominant.

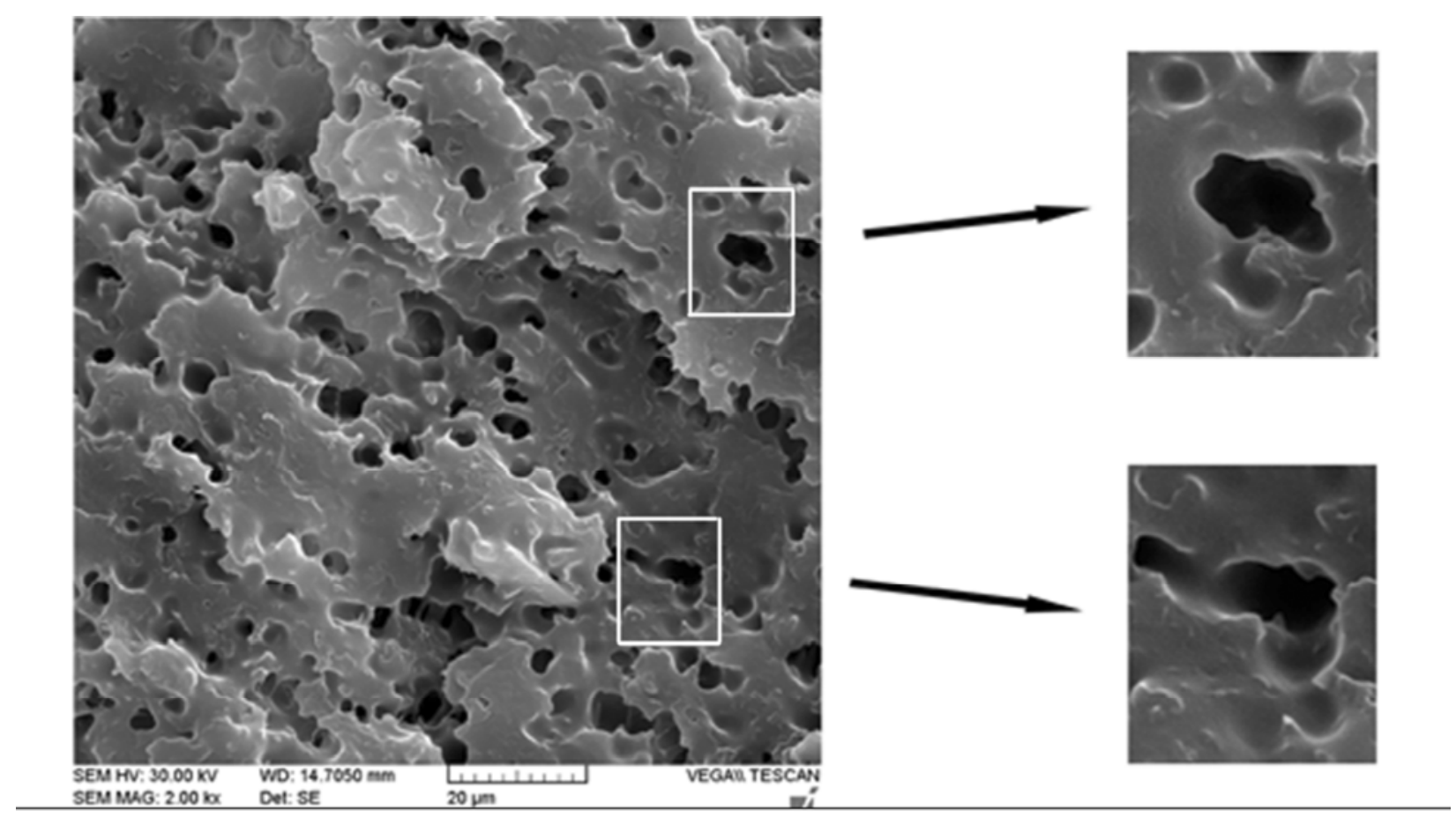

Fig. 9. Cell coalescences in the growing neighbour cells.

Nucleation efficiency of nanoparticle is a quantitative index for evaluating the influence of nanoparticle as a nucleating agent in the nanocomposite foam which is defined by the ratio of observed cell density to the potential cell density [36]. The potential cell density is given as [37]:

$\frac{\text { Nucleant }}{\mathrm{cm}^{3}}=\frac{w}{\rho_{p}} \frac{\rho_{\text {blend }}}{V_{p}}$ 
where $V_{p}$ is the volume of individual nanoclay, $P_{b l e n d}$ and $P_{p}$ are polymer and nanoclay densities and $w$ is the weight fraction of the nanoclay.

Tab. 4. Nucleation efficiency of Cloisite $15 \mathrm{~A}$.

\begin{tabular}{lll}
\hline Samples & Cell density & Nucleating efficiency \\
\hline $\mathrm{B}_{2}$ & $8.68 \mathrm{E}^{9}$ & $1.8 \mathrm{E}^{-5}$ \\
$\mathrm{~B}_{3}$ & $1.1 \mathrm{E}^{10}$ & $1.7 \mathrm{E}^{-5}$ \\
$\mathrm{~B}_{4}$ & $1.2 \mathrm{E}^{10}$ & $2.5 \mathrm{E}^{-5}$ \\
\hline
\end{tabular}

Table 4 shows the nucleation efficiency of cloisite $15 \mathrm{~A}$ in all nanocomposite samples at the constant foaming condition. Low nucleation efficiency values are obtained which could be attributed to the poor interaction between cloisite 15A and polymer blend. These results are in agreement with the high calculated gas-polymer-nanoclay contact angle. Dispersion of the nanoclays in the blend plays an important role. Thus, nucleation efficiency in $B_{4}$ is somehow better than $B_{2}$ and $B_{3}$ because of its exfoliation state. According to the classic nucleation theory, exfoliated morphology of nanoclays increase the nucleation sites $\left(C_{1}\right.$ in Equation (5)), and therefore more bubbles could be nucleated.

\section{Conclusions}

In this study, the quick heating method was used to prepare PP/EPDM/Organoclay microcellular foam. The experimental designs were carried out using Box-Behnken method. The responses surface methodology (RSM) was employed to investigate the effective parameters. The cell density and the average cell diameter were selected as model responses, while foaming pressure, foaming time and nanoclay concentration were chosen as the effective parameters. The results showed that higher cell density and smaller cell size were achieved by increasing foaming pressure and nanoclay loading. These trends were observed in all foaming time levels and $5 \mathrm{~s}$ was found to be the best foaming time level. Polymer-gas-nanoclay contact angle $(\theta)$ was calculated according to surface tension measurements. Although the calculated $\theta$ was high the mathematical model and the response surface graphs revealed that the nanoparticles had more considerable effect on the cell density and the average cell diameter compared with the other parameters. Effect of nanoclay dispersion was discussed by means of nucleation efficiency. The results showed that the $B_{4}$ sample with exfoliated morphology had the best nucleating efficiency among all samples.

\section{Experimental}

\section{Materials}

Polypropylene (PI0800) with MFI of $8 \mathrm{gr} / 10 \mathrm{~min}$ was supplied by Bandar Imam Petrochemical Co, Bandar Imam, Iran. EPDM KEP270 containing 57\% ethylene and $4.5 \%$ ENB was manufactured by Kumho Polychem, Seoul, Korea. The nanoclay employed in this study was Cloisite 15A, a natural montmorillonite modified with dimethyl, dehydrogenated tallow (2M2HT) a quaternary ammonium salt- from Southern Clay, Texas, USA. The initial gallery height (d001) was $31.5 \AA$. Maleic anhydride grafted polypropylene (MA-g-PP) as a compatibilizer was manufactured by 
priex 20070, Solvey, Brussels, Belgium. $\mathrm{N}_{2}$ gas with a purity of $99.9 \%$ was purchased from a local market.

All materials were used as received except nanoclay which was dried in a vacuum oven at $70{ }^{\circ} \mathrm{C}$ for $6 \mathrm{~h}$ before processing.

\section{Nanocomposite preparation}

Compounding was performed by means of a Brabender internal mixer with roller blade rotor (Plasticorder, Germany) operating at a rotor speed of $60 \mathrm{rpm}$ and $190{ }^{\circ} \mathrm{C}$.

PP was first fed into the mixing chamber, and EPDM was added after PP melting. The MA-g-PP and the nanoclay were incorporated into the compound after 2 minutes and mixing continued for 12 minutes. After compounding, the samples were dumped out and processed by compression molding (Toyoseki, Japan) at $200{ }^{\circ} \mathrm{C}$ and $15 \mathrm{MPa}$ into $1 \mathrm{~mm}$ thickness sheets. The compositions of the samples are listed in Table 5.

Tab. 5. The compositions of the samples.

\begin{tabular}{c|cccc}
\hline sample & PP(Phr) & EPDM(Phr) & $\begin{array}{c}\text { MA- } \\
\text { PP(Phr) }\end{array}$ & $\begin{array}{c}\text { Cloisite } \\
15 A(P h r)\end{array}$ \\
\hline$B_{1}$ & 50 & 50 & ----- & ----- \\
$B_{2}$ & 50 & 50 & 5 & 2 \\
$B_{3}$ & 50 & 50 & 5 & 4 \\
$B_{4}$ & 50 & 50 & 20 & 2 \\
\hline
\end{tabular}

\section{Microcellular foaming}

The quick heating method was used to foam the samples using a home-made autoclave with an electrical heater covering. The samples were saturated by $\mathrm{N}_{2}$ at constant temperature of $152{ }^{\circ} \mathrm{C}$. This temperature was chosen to achieve a shorter saturation time (approximately two hours). In the next step, a rapid pressure drop was imposed on the system and then the samples were kept in the vessel to be heated in predesigned foaming time. Finally, foam cells were fixed by purging the chamber with cold nitrogen. The duration between decompression and nitrogen purging was accounted as foaming time.

\section{Experimental design}

The experimental design was done according to Box-Behnken method [29] which is depicted in Table 6.

Tab. 6. The experimental design according to Box-Behnken method.

\begin{tabular}{llllllllllllllll}
\hline Run No. & 1 & 2 & 3 & 4 & 5 & 6 & 7 & 8 & 9 & 10 & 11 & 12 & 13 & 14 & 15 \\
\hline Pressure[bar] & 100 & 90 & 100 & 90 & 80 & 90 & 100 & 90 & 80 & 90 & 80 & 80 & 90 & 90 & 100 \\
\hline $\begin{array}{l}\text { Foaming } \\
\text { time[s] }\end{array}$ & 5 & 5 & 0 & 0 & 0 & 5 & 5 & 5 & 5 & 0 & 10 & 5 & 10 & 10 & 10 \\
\hline Nanoclay[Phr] & 0 & 2 & 2 & 4 & 2 & 2 & 4 & 2 & 0 & 0 & 2 & 4 & 0 & 4 & 2 \\
\hline
\end{tabular}


Three levels of saturation pressure, nanoclay content, and foaming time were chosen in this study.

This design is rotatable which means that all the points in the design area are at equal distance from the center points. The number of design points $(\mathrm{N})$ is calculated by the Equation:

$\mathrm{N}=2^{\mathrm{k}}+2 \mathrm{k}+\mathrm{m}$

where $\mathrm{k}$ and $\mathrm{m}$ are the number of factors and the number of replicates of the center points respectively. The replicate of center points is due to checking the reproducibility of the samples. The multiple linear regression analysis was used and the data were fitted as linear or second order equations.

Using response surface methodology with minimum number of experiments, it is possible to obtain quantitative equations for the effect of processing condition on the properties of nanocomposite microcellular foam.

The order of equations are specified based on the lack of fit test and maximizing simultaneously three parameters viz. $R^{2}$ (the $R^{2}$ values indicate the degree of agreement between the experimental results with those predicted by model).

A computer analysis has been done using commercially available package (MINITAB V13.2) to compute the equation constants.

\section{Measurements}

Cellular structure of the foamed samples was studied using scanning electron microscopy (SEM), Tescan VEGA-II, USA. All of the samples were immersed in liquid nitrogen and the cryogenically fractured surfaces were coated with gold. Unfoamed samples were etched by $n$-heptane for 24 hours to extract EPDM phase. The cell diameters of foamed samples were analyzed using Image $\mathrm{J}$, computer software, V1.43 from National Institute of Health. The average diameters of at least 20 cells are reported as cell diameter. The cell density, $\mathrm{N}_{\mathrm{f}}$, which is defined as the number of cells per unit volume, can be calculated from Equation 12 [5].

$$
N_{f}=\left(\frac{n M^{2}}{A}\right)^{\frac{3}{2}}
$$

where $\mathrm{n}$ is the number of bubbles observed in the SEM micrograph, $\mathrm{A}$ is the area of the picture $\left(\mathrm{cm}^{2}\right)$, and $M$ is the magnification factor.

X-ray diffraction (XRD) and transmission electron microscopy (TEM) were employed to characterize the nanocomposite structure. XRD analysis was conducted by a Hecus, S3-Micropix, Austria, with $\mathrm{Cu}$ beam $\left(40 \mathrm{kV}, 1 \mathrm{~mA}, \lambda=1.542 \mathrm{~A}^{\circ}\right)$ at room temperature.

TEM tests were performed on a EM 208, transmission electron microscopy (Phillips, Netherland) using an accelerating voltage of $100 \mathrm{kV}$. Samples were first Ultra Microtomed in liquid nitrogen with diamond knife.

The surface tensions were obtained by direct contact angle measurements using a G10, KRUSS, Germany apparatus. 70 $\mu$ m thickness films of PP and EPDM and a compressed tablet of Cloisite 15A were prepared for this purpose. Measurements 
were carried out using the Wu method; water and diiodo methane were used as a polar and nonpolar solvents, respectively.

\section{Acknowledgements}

The authors are very grateful for the financial support they received from the Iran National Science Foundation (INSF).

\section{References}

[1] Martini-Vvedensky, J.; Suh, N.; Waldman, F. Microcellular closed cell foams and their method of manufacture. 1984, Google Patents.

[2] Sumarno, T.; Sato, Y.; Takishima, S.; Masuoka, H., Polymer Engineering and Science. 2000, 40, 1510.

[3] Reglero Ruiz, J.; Viot, P.; Dumon, M. Journal of Applied Polymer Science. 2010, 118, 320.

[4] Arora, K.A.; Lesser, A.J.; McCarthy, T.J. Macromolecules. 1998, 31, 4614.

[5] Kumar, V.; Suh, N.P. Polymer Engineering \& Science. 1990, 30, 1323.

[6] Sumarno, Y.; Takishima, S.; Masuoka, H. Journal of Applied Polymer Science. 2000, 77, 2383.

[7] Tsivintzelis, I.; Angelopoulou, A.; Panayiotou, C. Polymer. 2007, 48, 5928.

[8] Goel, S.; Beckman, E. Polymer Engineering \& Science. 1994, 34, 1137.

[9] Jacobs, M.A.; Kemmere, M.F.; Keurentjes, J.T.F. Polymer. 2004, 45, 7539.

[10] Lim, H.; Kim, S.; Kim, B.

[11] Guo Linfeng, X.C. Zhu, J.; Wang, Y. e-Polymers. 2006, 064, 1.

[12] Yang, H.; Han, C. Journal of Applied Polymer Science. 1984, 29, 4465.

[13] Chen, L.; Blizard, K.; Straff, R.; Wang, X. Journal of cellular plastics. 2002, 38.

[14] Park, C.; Cheung, L.; Song, S. Cellular polymers. 1998, 17, 221.

[15] Colton, J.; Suh, N. Polymer Engineering \& Science. 1987, 27, 485.

[16] Colton, J.; Suh, N. Polymer Engineering \& Science. 1987, 27, 500.

[17] Shen, J.; Han, X.; Lee, L.J. Journal of cellular plastics. 2006, 42, 105.

[18] Khorasani, M.M.; Ghaffarian, S.R.; Babaie, A.; Mohammadi, N. Journal of cellular plastics. 2010, 46, 173.

[19] Zeng, C.; Hossieny, N.; Zhang, C.; Wang, B. Polymer. 2010, 51, 655.

[20] Zhu, B.; Zha, W.; Yang, J.; Zhang, C.; Lee, L.J. Polymer. 2010, 51, 2177.

[21] Urbanczyk, L.; Calberg, C.; Detrembleur, C.; Jérôme, C.; Alexandre, M. Polymer. 2010, 51, 3520.

[22] Zhai, W.; Yu, J.; Wu, L.; Ma, W.; He, J. Polymer. 2006, 47, 7580.

[23] Shen, J.; Zeng, C.; Lee, L. Polymer. 2005, 46, 5218.

[24] Chen, L.; Ozisik, R.; Schadler, L. Polymer. 2010, 51, 2368.

[25] Lee, Y.H.; Wang, K.H.; Park, C.B.; Sain, M. Journal of Applied Polymer Science. 2007, 103, 2129.

[26] da Silva, A.L.N.; Coutinho, F.M.B. Polymer Testing. 1996, 15, 45.

[27] Zhang, Z.; Zhang, S.; Xin, Z. e-Polymers. 2007, 132, 1.

[28] Wong, S.; Naguib, H.E.; Park, C.B. Advances in Polymer Technology. 2007, 26, 232.

[29] Ghasemi, I.; Karrabi, M.; Mohammadi, M.; Azizi, H. Express Polymer Letters. 2010, 4, 62.

[30] Fletcher, N. The Journal of chemical physics. 1958, 29, 572.

[31] Vehkamäki, H. Berlin: Springer Verlag, 2006.

[32] Kim, J.; Friend, R.; Cacialli, F. Synthetic Metals. 2000, 111, 369. 
[33] Wu, S. New York: CRC, 1982.

[34] Lewin, M.; Mey Marom, A.; Frank, R. Polymers for Advanced Technologies. 2005, 16, 429.

[35] Zhang, Z.X.; Zhang, S.L.; Lee, S.H.; Kang, D.J.; Bang, D.S.; Kim, J.K. Materials Letters. 2008, 62, 4396.

[36] Riahinezhad, M.; Ghasemi, I.; Karrabi, M.; Azizi, H. Journal of Vinyl and Additive Technology. 2010, 16, 229.

[37] Spitael, P.; Macosko, C.W.; McClurg, R.B. Macromolecules. 2004, 37, 6874. 